\title{
EVENTS
}

\section{Summary Report of the 4th International Congress of Person Centered Medicine, Person Centered Medical Education and the Goals of Health Care, Madrid, 7-9 November 2016}

\author{
Dr. Juan Perez-Miranda. Universidad Francisco de Vitoria (Madrid, Spain)
}

\section{Day 1: Monday November 7th}

The opening of the $4^{\text {th }}$ International Congress of Person Centred Medicine took place in the Main Auditorium of Francisco de Vitoria University in Madrid, Spain. Welcoming words were offered by Jim Appleyard and Juan Mezzich representing the ICPCM as well as by Fernando Caballero (Dean of the Medical School) and Juan Perez-Miranda (Vice-Rector for International Affairs) from Francisco de Vitoria University.

Professors Mezzich and Appleyard stressed the importance of this congress in connecting person centered medical education with the goals of health care. Professor Caballero delivered the inaugural conference expressing the need for a new model of Person-Centered Medical Education and had the opportunity to explain in detail the experience of setting up a new medical school under this model. Over 300 people, including congress participants as well as students and professors from Francisco de Vitoria University attended the opening session of the congress.

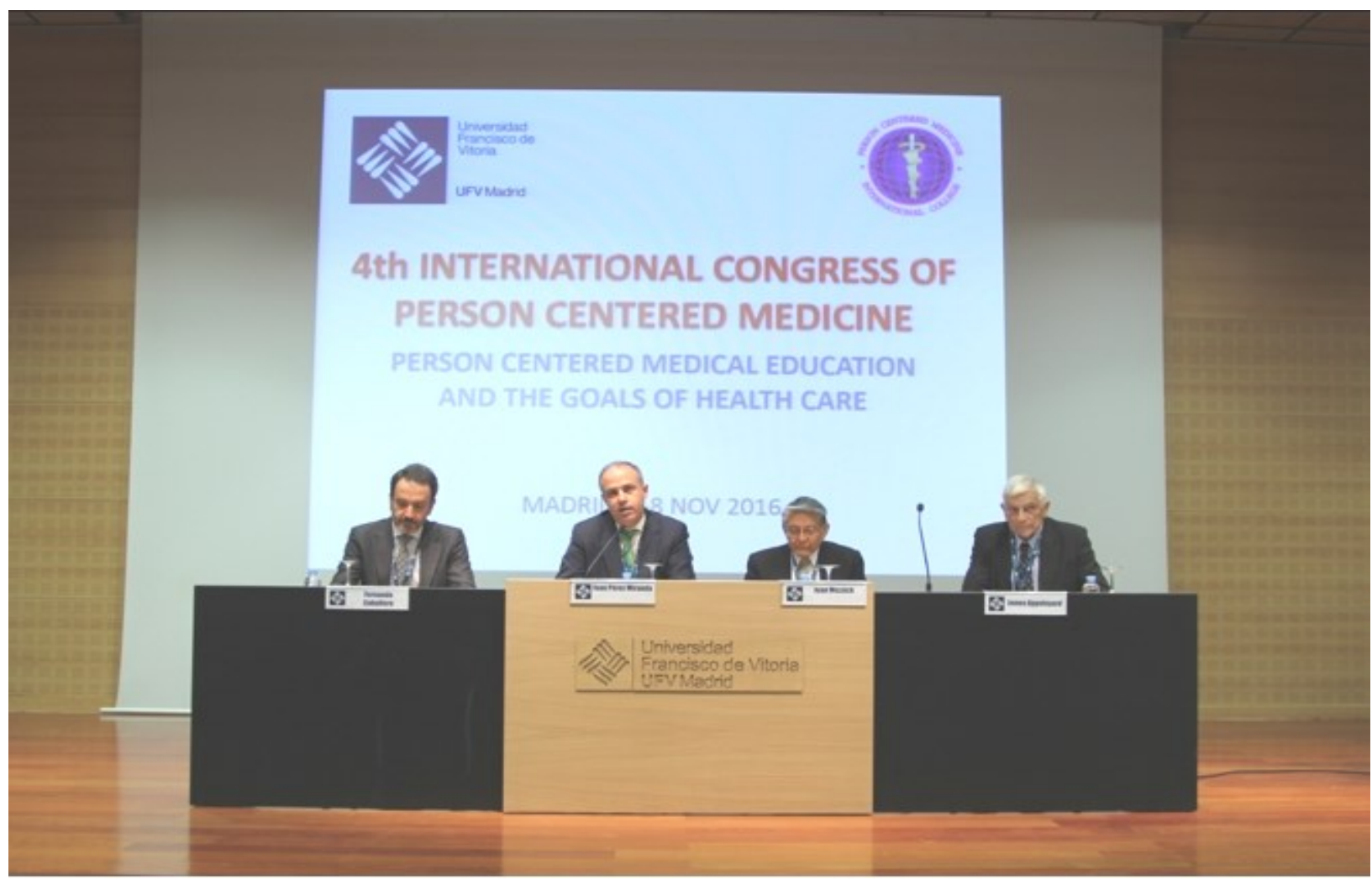

LtoR: Profs. Fernando Caballero, Juan Perez-Miranda, Juan Mezzich and Jim Appleyard opening the Congress

Professors Alberto Perales (Lima) and Ricardo Abengozar (Madrid) chaired the first Round Table, debating the concepts of Humanism and Humanities, the ethical bases of Person-Centered Medical Education and the principles and values this emerging perspective.

During the first series of Parallel Sessions, two workshops were organized: one about the "Madrid Declaration on Person-Centered Medical Education and the goals of healthcare", co-chaired by professors Fernando Caballero (Madrid) 
and Jim Appleyard (London), and the second Parallel Session was about clinical complexity and contextualization, cochaired by professors Roger Ruiz Moral (Madrid) and Michel Botbol (Brest, France).

The main aim of the Madrid Declaration workshop was to recognize the compelling need to promote full health for all by transforming in a person-centered manner the way health-care professionals are educated. The Declaration builds on the work of previous conferences and congresses on person-centered medicine, particularly those addressed to advance health professional education centered on the whole person.

During the second set of Parallel Sessions, professors Cristina Garcia de Leonardo (Madrid) and Tesfa Ghebrehiwet (Alberta, Canada) co-chaired the first workshop on the practical elements of the UFV Person-Centered Medical Education model, which included student and patient experiences. On the second workshop, co-chaired by Ricardo Abengozar (Madrid) and Ihsan Salloum (Miami) a lively debate on bioethical dilemmas took place considering the perspective of the whole person and human dignity.

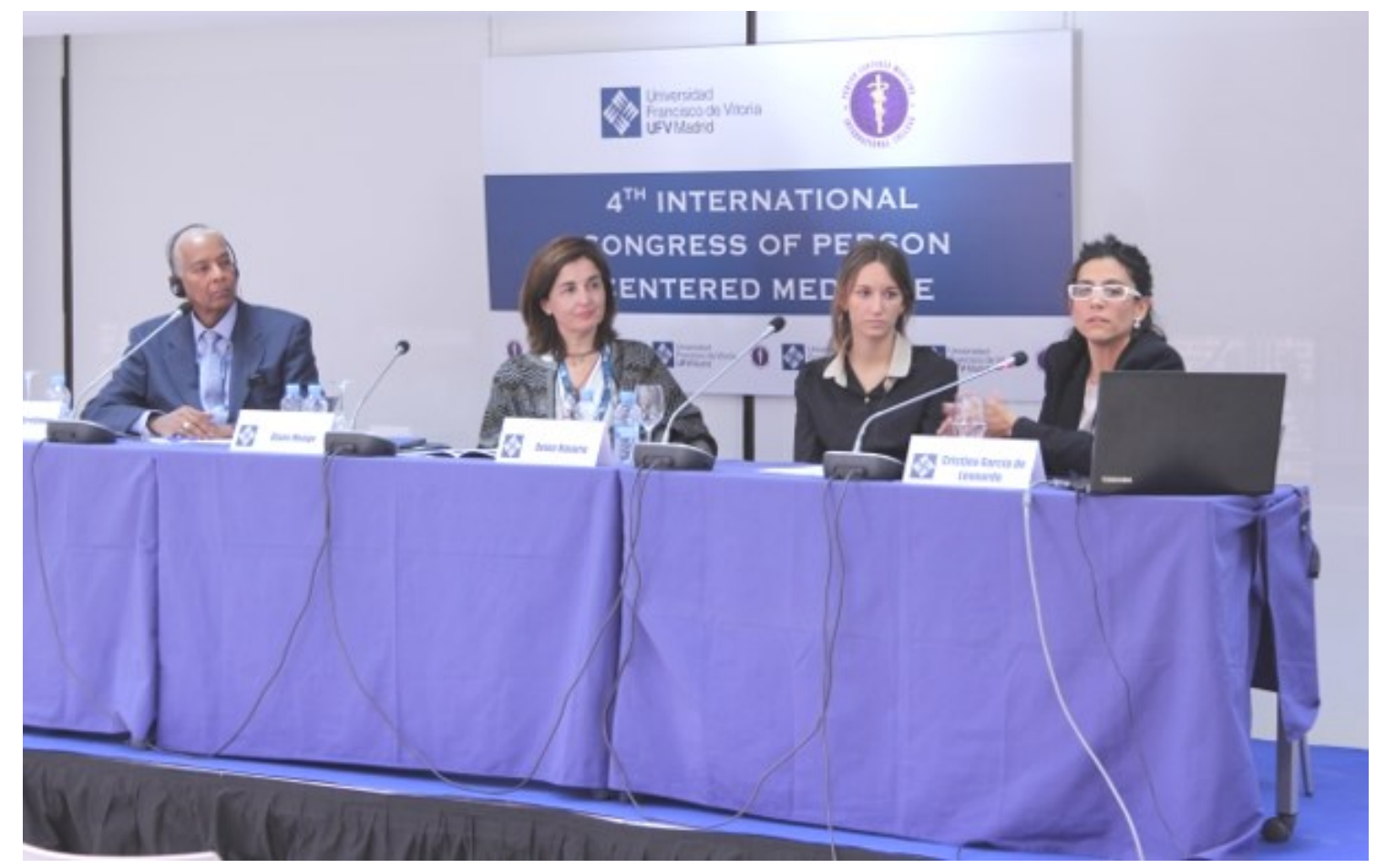

LtoR:Profs Tesfa Ghebrehiwet and Cristina Garcia de Leonardo, Student Belen Navarro and Prof. Diana Monge

The last Round Table of the first day was about people-centered Public Health, ecology and Social Determinants of Health, co-chaired by Diana Monge (Madrid) and Sandra Van Dulmen (Nijmegen, The Netherlands). The perspectives for the debate were enriched by the international profile of the selected panel of experts, including SubSaharan Africa with Werdie Van Staden (Pretoria, South Africa), the Americas with Freddy Canchihuaman (Lima, Peru) and Oceania with Luis Salvador-Carulla (Sydney, Australia).

\section{Day 2: Tuesday November 8th}

The second day of the congress opened with a Round Table about the topic of doctor-patient relationship as the core of humanizing clinical practice, co-chaired by professor Roger Ruiz Moral (Madrid) and Joanna Groves (London). The discussions and debates were organized around the role of physicians and other health professionals in the humanization of clinical care by Alberto Perales (Lima, Peru), humanism and humanities in the context of the doctor-patient relationship by Florentino de Araujo Cardoso (Brazilian Medical Association), communicational approaches to enhance the doctor-patient relationship by Ronald Epstein (Rochester, NY, USA), clinical communication and doctor-patient relationship by Sandra Van Dulmen (Nijmegen, The Netherlands) and setting a common ground for joint diagnostic understanding and shared decision making by Juan Mezzich (New York). 


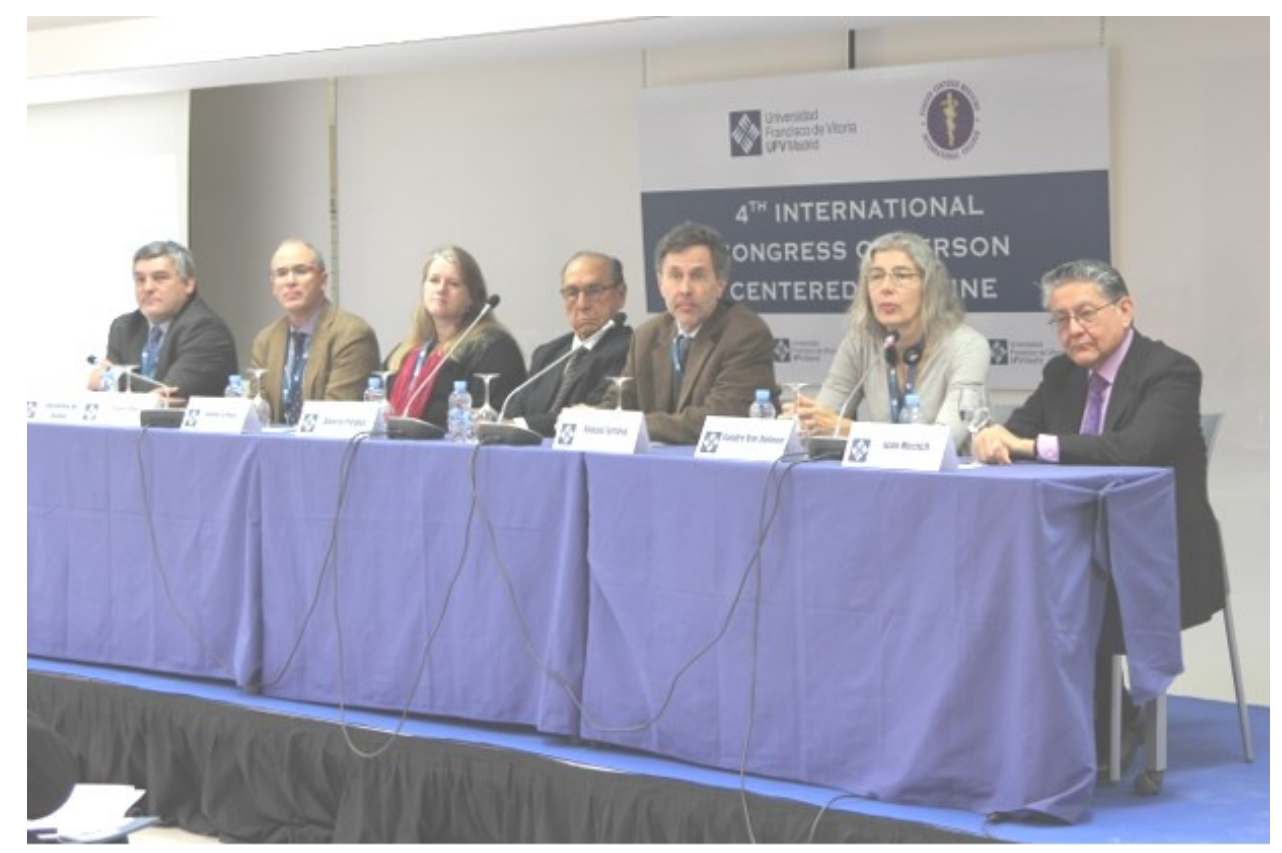

LtR: Professors Florentino de Araujo, Roger Ruiz Moral, Joanna Groves, Alberto Perales, Ronald Epstein, Sandra Van Dulmen and Juan Mezzich

The second Round Table of the day considered the topic of clinical communication and simulation methods in medical education, and was co-chaired by professors Fernando Caballero (Madrid) and Jim Appleyard (London). The main areas of debate were patient safety and clinical simulation, the importance of clinical simulation in undergraduate medical education as a tool to train future generations of doctors, a proposal for a core curriculum on clinical communication for undergraduate medical studies, and inter-professional communication and collaboration.

At noon, a special Inter-institutional Colloquium on Ibero-American perspectives on Person Centered Medicine took place, conducted by the well-known radio and TV Spanish journalist Ernesto Saez de Buruaga. Members from prestigious institutions participated in a lively discussion about the professional values of medical practice and the relevance of person centeredness. The participant institutions were the Spanish Royal Academy of Medicine, the Spanish National Medical Deans Conference, the Brazilian Medical Association, the Latin American Association of National Academies of Medicine, the Latin American Network of Person Centered Medicine, and the International College of Person Centered Medicine.

After the lunch break, different sessions of brief Oral Presentations took place covering areas like: Health coaching and medical student curriculum, evaluating empathy in medical residency applicants, a questionnaire on humanism in healthcare, medical student training on empathy, Person-Centered interviewing for non-expressed experiences, mentorship for professionalism \& personal growth, contextualizing patient-centered primary care in Uganda and Person-Centered services from academia to prisons.

During the afternoon of the second day, three thematic workshops were organized covering the following topics: (1) Empathy and narrative training to engage patient's subjectivity in clinical practice, co-chaired by Sandra Van Dulmen (Nijmegen, the Netherlands) and Ronald Epstein (Rochester, New York). (2) Mindfulness, co-chaired by Michel Botbol (Brest, France) and Roger Ruiz Moral (Madrid). (3) Student and patient feedback on communication, co-chaired by Sophia Denizon (Madrid) and Tesfa Ghebrehiwet (Alberta, Canada).

The last Round Table of the second day was about the articulation of Person-Centered Medical Education and the goals of health care, co-chaired by professors Juan Perez-Miranda (Madrid) and Juan Mezzich (New York). The main topics and speakers were Medical Schools perspectives by Jim Appleyard (ICPCM, IAMC, London), educators perspectives by Brigida Marta (Bologna, Italy), Health planners perspectives by Cristina González del Yerro (Regional Health Department, Madrid), students perspectives by Alejandro Iñarra Navarro (Spanish Confederation of Medical Students) and patient associations perspectives by Joanna Groves (London).

At the closing session, professors Fernando Caballero, Juan Perez-Miranda and Jim Appleyard presented the $4^{\text {th }}$ International Congress of Person Centred Medicine main conclusions and the final draft of the Madrid Declaration, which was adopted by the participants. Finally, and invitation to the 5th International Congress of Person Centred Medicine that will take place in Zagreb during 2017 was presented to all congress participants by professors Djordjevic and Bras from (Zagreb, Croatia). After that, the chairs or the Closing Session formally closed the second day of the Congress. 


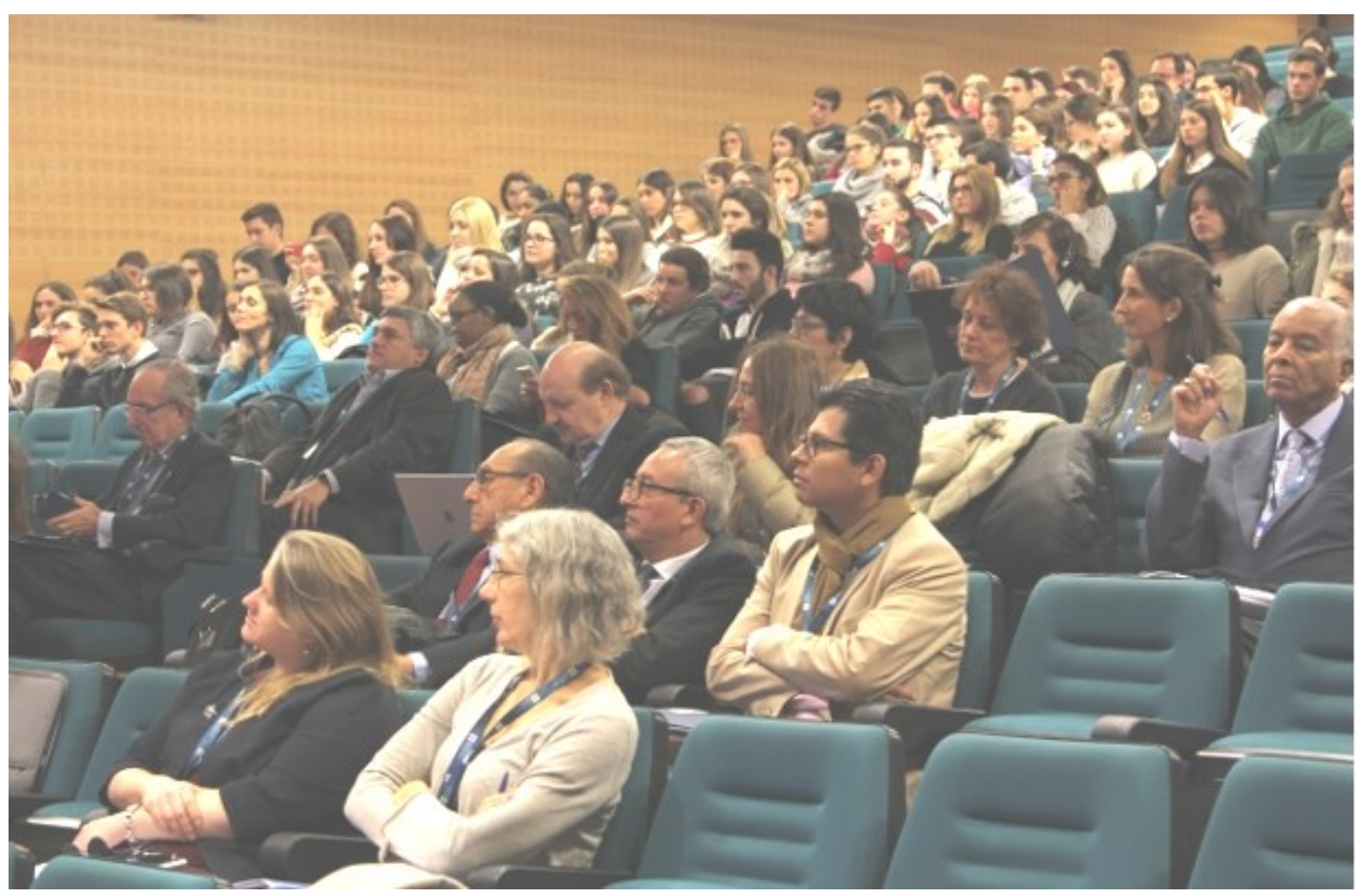

Partial view of the auditorium at the $4^{\text {th }}$ Int'l Congress on Person Centered Medicine in Madrid

\section{Day 3: Wednesday November 9th}

The last day of the Congress was planned as a Working Session on Person-Centered Medicine. The two hours of the working session represented an opportunity to discuss the future agenda for advancing Person-Centered Medicine and ways for implementing the conclusions of the Congress and the Madrid Declaration. The Declaration calls on educational institutions, associations of health professionals, medical colleges, and governmental and inter-governmental organizations to collaborate in improving health systems across the world by centering them on the person through medical education programs in graduate, post-graduate and continuing medical education activities. All participants agreed on the fruitful and productive meetings during the Congress and the future impact that the Madrid Declaration will have in orienting and inspiring the education of future doctors. 